\title{
Claves psicológicas fundacionales del autogobierno ciudadano: la "psicología del pueblo español” como estudio de caso (1902-1918)*
}

Foundational Psychological Clues of Citizenry Self-Government: the
"Psychology of the Spanish People" as a Case Study (1902-1918)

Recibido: diciembre 3 de 2013 | Revisado: febrero 2 de 2014 | Aceptado: julio 28 de 2014

\author{
Jorge Castro Tejerina ** \\ Universidad Nacional de Educación a Distancia, \\ Madrid, España
}

doi:10.11144/Javeriana.upsy13-5.cpfa

Para citar este artículo: Castro, J. (2014). Claves psicológicas fundacionales del autogobierno ciudadano: la "psicología del pueblo español" como estudio de caso (1902-1918). Universitas Psychologica, 13(5), 1739-1753. http://dx.doi.org/10.11144/ Javeriana.upsy13-5.cpfa

- Agradecimientos: Este trabajo se enmarca en el proyecto de investigación "La psicología de la ciudadanía: fundamentos histórico-genealógicos de la construcción psicológica del autogobierno y la convivencia en el Estado español", financiado por el Ministerio de Economía y Competitividad del Gobierno de España (código PSI2011-28241).

** Facultad de Psicología. Juan del Rosal 10, 28040. Madrid, España.Correo electrónico: jorge.castro@ psi.uned.es

\section{RES U MEN}

A finales del siglo XIX y principios del XX, la configuración psicológica del concepto liberal de autogobierno fue clave para diseñar el sujeto político de la modernidad y la propia idea de "ciudadanía". Nuestro trabajo estudia ese proceso sociohistórico a través de los primeros textos dedicados a la "psicología del pueblo español". Además de confirmar la estrecha relación entre psicología y autogobierno, el análisis revela el papel de la psicología en la transición histórica desde las tradicionales teorías y prácticas de la subjetividad hasta las modernas -particularmente en el dominio educativo y religioso-. Gracias a la psicología, el proyecto liberal también estableció los supuestos límites sociopolíticos para la potencial participación ciudadana de la población española.

Palabras clave

psicología de la ciudadanía; autogobierno; psicología del pueblo español; teorías y prácticas de la subjetividad

\section{A B S T R A C T}

At the end of the 19th Century and the beginning of the 20th, the psychological configuration of the liberal concept of self-government was basic to design the political subject of the modernity and the very idea of "citizenship". Our paper studies this socio-historical process throughout the first works devoted to the "Psychology of the Spanish People". The analysis not only confirm the close relation between psychology and citizenship, but the role played by the psychology in the transition from the traditional theories and practices of the subjectivity to the modern ones - particularly in the fields of religion and education. The socio-political limits imposed by the liberal program on the potential citizen participation of the Spanish population are also revealed.

Keywords

psychology of citizenship; self-government; psychology of the Spanish People; theories and practices of subjectivity 


\section{Psicología y ciudadanía: un marco de trabajo genealógico a propósito del autogobierno}

Este trabajo se enmarca en una línea de trabajo genealógico que trata de rastrear los aspectos teóricos y prácticos que estuvieron relacionados con el discurso psicológico, a la hora de diseñar el sujeto de la ciudadanía a principios del siglo XX. En él estudiaremos obras pertenecientes al género de la psicología del pueblo español publicadas entre 1902 y 1918, para analizar el modo en que estas abordaron la cuestión del autogobierno en el caso del ciudadano español.

De manera genérica, el término ciudadanía se asocia actualmente a una serie de valores relacionados con la participación activa, directa, reflexiva y responsable de cualquier persona en los diferentes niveles de su comunidad política de referencia, particularmente, en lo que toca a las decisiones relacionadas con las formas de convivencia y responsabilidad social (Heater, 2004). Su distanciamiento de fundamentos territoriales y antropológicos específicos, a la hora de definir la condición de ciudadano, implica también cierta aspiración para promover la universalización del modelo, colocándolo, no sin controversias y contradicciones (Purvis \& Hunt, 1999), más allá de las condiciones y restricciones legislativas peculiares de cada Estado nación (Kymlicka, 1995). Sea como fuere, lo interesante desde el punto de vista histórico es que esta figura ciudadana se empezó a componer a partir del último tercio del siglo XIX, dentro del progresismo democrático liberal y al calor de miradas pacifistas, humanistas y utopistas.

Aunque sin una referencia concreta a esta condición "ciudadana", la sensibilidad genealógica que autores como Nikolas Rose o Florentino Blanco despliegan sobre las funciones socioculturales y sociohistóricas de la psicología convergen bien con ella (Blanco, 2002; Foucault, 2007; Rose, 1989, 1996). Para estas perspectivas, desde finales del siglo XIX, las tecnologías psicológicas (educativas, clínicas, criminológicas, laborales, etc.) trabajarán, entre otras posibilidades, para que el sujeto de las democracias occidentales interiorice sistemas de control y dirección del propio comportamiento. El objetivo será el autogobierno de la propia conducta en ausencia de vigilancia y punición externa e institucional continua (Foucault, 2000). Al tiempo, los fines de la acción personal serían tematizados y promovidos al servicio de valores como la felicidad, la autonomía o la libertad, entre otras posibilidades seculares (Miller \& Rose, 2008).

Nuestra perspectiva se coloca también dentro de este marco genealógico, pero aspira a matizar el proceso genérico de "psicologización del autogobierno" que lo preside en varios puntos. Así, tal y como esquematizamos en la Figura 1, el sujeto político moderno habitaría una encrucijada de tensiones e hibridaciones que impiden definir una imagen homogénea o monolítica de la subjetividad autogobernada. Entre otras cuestiones, esta mantiene una continuidad operativa inevitable con prácticas y discursos sobre el Yo muy diversos, además de temporalmente previos desde el punto de vista histórico-cultural.

El sujeto que se autogobierna gracias a la tecnologías psicológicas será inherente al proceso sociohistórico por el que países como Francia, Italia, España, Argentina, Brasil o Japón se incorporan a una suerte de "occidentalización" inspirada, en mayor o menos medida, en las formas de gobierno democrático y liberal típicamente anglosajonas (Castro \& Lafuente, 2007). Sin embargo, como se deduce de la Figura 1, desde sus propios orígenes esa lógica del autogobierno se define inevitablemente respecto de condiciones socioculturales específicas en cada país.

Entre otras cuestiones, a finales del siglo XIX y principios del XX, la conciencia de esa diversidad se asimila al presupuesto positivista que permite estimar, ordenar, comparar y baremar las psicologías, caracteres o temperamentos de los diferentes colectivos nacionales respecto de un supuesto "ideal civilizado". Como bien ha estudiado Glenda Sluga (2006), esto permitirá que, por ejemplo, las negociaciones de paz, que tuvieron lugar en París al finalizar la Primera Guerra Mundial, se produjeran sobre argumentos relativos a la mayor o menor madurez caracteriológica de las razas o etnias $-\mathrm{y}$, por ende, de los individuos-que poblaban los diferentes 


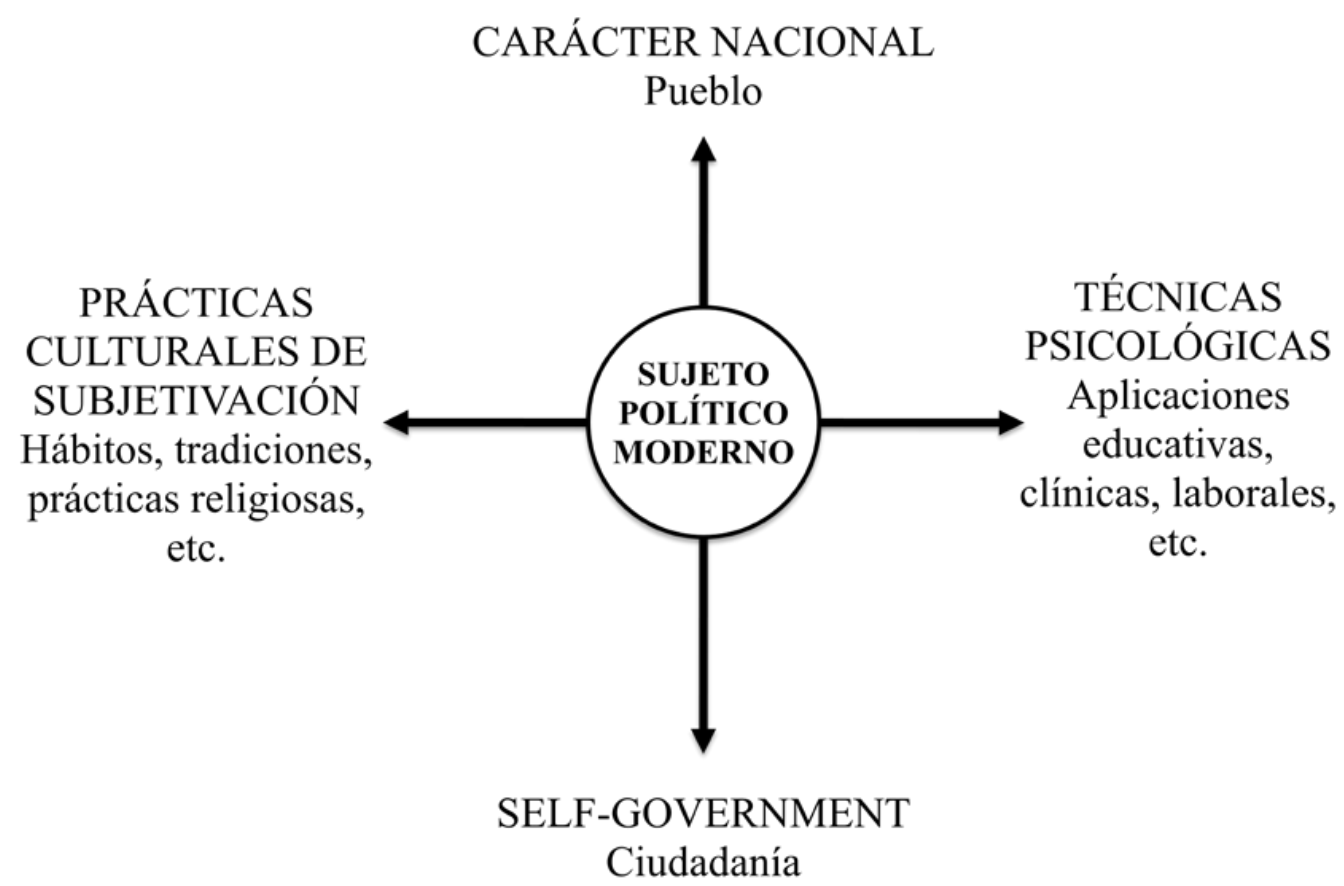

Figura 1. Discursos y prácticas sobre la subjetividad moderna

Fuente: elaboración propia

países del mundo. Tal criterio informó, en buena medida, de las posibilidades de autodeterminación o tutela colonial de cada país, definiendo el reparto de influencias internacionales entre las potencias ganadoras de la Gran Guerra.

En realidad, aunque el juego de alineaciones y los protagonistas implicados no sea exactamente los mismos, el marco etnopsicológico que ofrece las condiciones para esta baremación y reordenación de influencias internacionales se había fraguado ya a finales del siglo XIX. Es instituido por autores como Giusseppe Sergi (1841-1936), Max Nordau (1849-1923) o Edmond Demolins (1852-1907), a través de una serie de obras que presentan la dicotomía de unos pueblos anglosajones en pleno auge neocolonial -atribuido, entre otras cuestiones, a la alta aportación aria en su constitución racial-y unos pueblos latinos representantes del viejo imperialismo en decadencia -en parte explicada por el componente semítico de su configuración antropofísica-. En todo caso, un criterio comparativo tan importante como la relevancia o influencia internacional fue el que estimaba el ajuste de los distintos países al modelo de progreso y producción industrial. En último término, este estaba asociado a un consecuente y relativo aumento del bienestar en todas las clases sociales, algo que, nuevamente, la mayoría de los intelectuales de principios de siglo asociaban a países como Norteamérica o Gran Bretaña.

\section{La "psicología del pueblo español" como estudio de caso}

En todos los países occidentales o en vías de occidentalización, las cuestiones comentadas conducirán a las clases ilustradas -intelectuales, periodistas, académicos, etc.- a realizar una reflexión muy similar. El objetivo será establecer hasta qué punto las psicologías nacionales de sus respectivos países estaban preparadas para afrontar el reto de la modernidad por sí mismas. En España, esa reflexión estuvo representada en primera instancia por los así llamados regeneracionistas. Entre otros muchos, podemos señalar al jurista e historiador Joaquín Costa (1846-1911), al educador y periodista 
Ricardo Macías Picavea (1847-1899), al periodista Luís Morote (1862-1913) o al ingeniero Lucas Mallada (1841-1921). Todos ellos fueron intelectuales de profesiones liberales y filiación progresista no exenta de heterodoxias ideológicas que, entre 1885 y 1899 , dieron lugar a un género literario dedicado a la decadencia y degeneración del pueblo español ${ }^{1}$. La tabla que sigue recoge algunas de las obras más significativas del género.

Todas las obras señaladas son bien conocidas y han sido analizadas en múltiples ocasiones desde diversos puntos de vista (Morón, 1998; Varela, 1999), incluyendo la historiografía de la psicología (véase, por ejemplo, Carpintero, 1998; Castro, 2004; Quintana, 1998). Resumiendo el argumento básico, señalaremos que este se centraba en el atraso políticoeconómico de España en comparación con las potencias occidentales. Tal preocupación se vería simbólicamente ratificada en 1898, año en que, tras más de 400 años de presencia imperialista, España perdía sus últimas colonias de Cuba y

1 Alternativamente, también se puede hablar de un proceso paralelo y dialógico de construcción psicológica de la nación española en clave eminentemente conservadora e, incluso, reaccionaria. En este caso, el proceso identitario se basaría en la continuidad con la tradición imperial y católica de España. La psicología como teoría y tecnología de la subjetividad nacional es, en todo caso, un recurso fraguado e impulsado por el nacionalismo liberal (sobre estas cuestiones se puede consultar Castro, Lafuente, \& Jiménez, 2009).

TABLA 1

Títulos más importantes del regeneracionismo
Filipinas frente al empuje del nuevo imperialismo estadounidense. En línea con todo lo comentado, para los regeneracionistas las claves que explicaban tanto la decadencia y el final del viejo imperio como las vías para la recuperación como Estado nación liberal y moderno, tenían un marcado carácter psicológico. De hecho, en 1900, el prestigioso historiador Rafael Altamira escribe una obra que, significativamente, titulará La psicología del pueblo español, y que, hasta cierto punto, supondrá no tanto el colofón del regeneracionismo como un punto de inflexión fundamental para el género (Altamira, 1902/1997) $)^{2}$.

Compartiendo análisis y conclusiones muy similares a las de otras obras regeneracionistas, lo más

2 Rafael Altamira fue importante historiador español vinculado al krausismo y la Institución Libre de Enseñanza, el valuarte de la educación liberal y progresista entre 1876 y 1936, año en que la Guerra Civil española puso fin a la andadura institucionista. Altamira destacó por su labor diplomática y cultural más allá de las fronteras españolas, siendo un reconocido americanista -fue nombrado doctor honoris causa por diversas universidades latinoamericanas, además de otras muchas europeas y estadounidenses-. Además, ocupó importantes cargos en diversas instituciones jurídicas europeas en el periodo entre guerras, como el Tribunal de la Haya. Fue un militante pacifista, y llegó a ser propuesto para el premio Nobel de la Paz. Su compromiso liberal, progresista y republicano le costó el exilio en México tras la victoria del bando franquista en 1939. Otras obras reseñables de Altamira son Historia de España y de la civilización española (1900-1911), Mi viaje a América (1911) y La huella de España en América (1924) (sobre la vida y obra de Altamira puede consultarse Alberola, 1987).

\begin{tabular}{lcc}
\hline \multicolumn{1}{c}{ TÍTULOS } & AUTORES & AÑO \\
\hline España tal como es & Valentí Almirall & 1889 \\
Los males de la patria & Lucas Mallada & 1890 \\
Idearium español & Angel Ganivet & 1897 \\
El desastre nacional y sus causas & Damián Isern & 1899 \\
El problema nacional & R. Macías Picavea & 1899 \\
Hacia otra España & Ramiro Maeztu & 1899 \\
La moral de la derrota & Luis Morote & 1900 \\
Reconstitución y europeización & & 1898 \\
Crisis política de España & Joaquín Costa & 1901 \\
Oligarquía y caciquismo & & 1901 \\
En torno al casticismo & Miguel Unamuno & 1902 \\
La psicología del pueblo español & Rafael Altamira & 1902 \\
\hline
\end{tabular}

Fuente: elaboración propia 
interesante del libro de Altamira es que, con él, el sujeto colectivo y sus condiciones psicológicas pasa literalmente a un primer plano (véanse Llavona \& Bandrés, 1999; Rodríguez, Sitges, Jarabo, Estévez, \& Brisoire, 2002). Ante todo, el texto convierte la referencia psicológica en el centro de atención y en el engranaje sobre el que, inevitablemente, habrá de girar ya cualquier modelo de gobierno y convivencia propuesto para el país a partir de $1902^{3}$. Esta "psicologización" radical de la cuestión nacional prendió inmediatamente en los intelectuales españoles que, en línea con el espíritu regeneracionista, se sumaron al tratamiento de la cuestión social española entre 1902 y el estallido de la Guerra Civil Española en 1936. Entre ellos podemos destacar a autores de relativa envergadura teórica dentro de la historia del pensamiento español, como el sociólogo Manuel Sales y Ferré (1843-1910) ${ }^{4}$, el psicólogo Eloy Luis André (1878-1935)5 o el historiador Salvador de Madariaga (1886-1978) ${ }^{6}$; al tiempo que otros menos

3 Aunque el libro de Altamira se publica en 1902, sus capítulos ya eran bien conocidos por la intelligentsia liberal española, ya que habían aparecido tres años antes y por entregas en La España moderna. Esta revista estaba asociada a una importante editorial española que, además de la publicación periódica, impulsó numerosas traducciones de libros extranjeros. Se fundó en 1889 y continuó publicando ininterrumpidamente hasta 1919, siempre con el objetivo explícito de modernizar la cultura española a imagen y semejanza de la europea (véase Yeves, 2002).

4 Manuel Sales y Ferré fue el más prestigioso sociólogo español de finales del siglo XIX y principios del XX. Educado en la filosofía krausista de la historia, evolucionó hacia posiciones positivistas, materialistas y darwinistas ganándose la crítica de muchos de compañeros de credo filosófico. Entre sus obras más destacadas cabe mencionar El hombre primitivo y las tradiciones orientales (1881), Tratado de sociología (1889-1904) y, en clave netamente regeneracionista, Problemas sociales (1910) (sobre la vida y obra de Sales puede consultarse a Núñez Encabo, 1976).

5 Eloy Luis André fue discípulo de Wilhelm Wundt y Rudolf Eucken y catedrático de filosofía de diversos institutos españoles. Compatibilizó la publicación de numerosos y cuidados textos académicos con una ingente obra ensayística en la que reflexionó sobre la política, la cultura y la identidad española y gallega. Entre sus obras más importantes figuran Ética española (1910), Dos idearios y dos democracias (1919) y Españolismo: prasologio (1931) (sobre la vida y obra de Luís André puede consultarse: Castro, 2008)

6 Salvador de Madariaga y Rojo fue un diplomático pacifista que desarrolló trabajos de asesoramiento para la Sociedad de Naciones. Escribió varios trabajos sobre la psicología de diversos pueblos europeos. Sus convicciones republicanas le costaron el exilio tras la Guerra Civil española, dedicando buena parte de sus esfuerzos a combatir la dictadura del general Franco desde el extranjero. Con todo, sus estudios históricos sobre Hispanoamérica fueron recibidos y criticados como una reivindicación del colonialismo relevantes o populares como Gustavo La Iglesia ${ }^{7}$ o el Marqués de Dosfuentes (1872-1955) ${ }^{8}$.

Estos dos últimos nombres formarían parte de una amplia nómina de autores menores que, con excepciones, publicaron sus obras en editoriales relativamente modestas, sin grandes tiradas ni expectativas de reedición y, en algún caso, de manera autofinanciada ${ }^{9}$. Con todo, el volumen y la coincidencia temática y argumental de todas estas obritas fue suficiente para constituir, evidenciar y popularizar un género editorial reconocible a propósito de la "psicología del pueblo español". Efectivamente, con independencia de su mayor o menor calidad o difusión, todos los tratados que recuperamos en este artículo incorporaron de manera preeminente categorías psicológicas en sus títulos y epígrafes a la hora de tratar la realidad social española. Raza, carácter, etnografía, conciencia, temperamento, alma, personalidad o, propiamente, psicología son algunos de los términos utilizados. La Tabla que sigue muestra una amplia selección de las obras de este tipo que se publicaron entre las fechas señaladas.

Si bien, como hemos señalado, todas estas obras emplean las referencias psicológicas para definir los

español. Entre sus obras cabe mencionar Bosquejo de Europa (1951) El ocaso del imperio español en América (1956), España. Ensayo de historia contemporánea (1978) (para la vida y obra de Salvador de Madariaga puede verse Casas, 2009).

7 Gustavo La Iglesia y García fue un abogado que participó en la compilación y organización de diversos textos de consulta legal. Además, desarrolló una discreta labor dentro del ensayismo político a través de trabajos como Caracteres del anarquismo en la actualidad (1905), Tolstoismo y Anarquismo (1905) o Iniciativas individuales y sociales: obstáculos que se oponen en España a su desarrollo (1908).

8 Fernando Antón de Olmet, titular del Marquesado de Dosfuentes, desarrolló funciones de diplomático en diversos países europeos y latinoamericanos. Se convirtió en un apologeta de la cultura española a través de sus numerosos ensayos y escritos literarios. Obras suyas fueron La cuestión social (1891), Proceso de los orígenes de la decadencia española (1914) e Himnos íberos (1915).

9 Existieron numerosas editoriales españolas muy implicadas en la difusión del pensamiento político y científico moderno, tanto a través de obras originales como de traducciones de los grandes pensadores de finales del siglo XIX y principios del XX. La mayoría de estas editoriales prestaron, además, una atención especial a la dimensión psicológica y su valor a la hora de explicar fenómenos culturales, sociales y políticos (Quintana, Rosa, Huertas, \& Blanco, 1998). Además de La España moderna, entre las editoriales más importantes pueden mencionarse Daniel Jorro, La Lectura, Victoriano Suárez, Minerva o Sucesores de Rivadeneyra. Solo las dos últimas aparecen entre las que editaron el tipo de obras a las que venimos haciendo referencia. 
TABLA 2

La "Psicología del pueblo español" como género

\begin{tabular}{|c|c|c|c|}
\hline TÍTULOS & EDITORIAL & AUTORES & AÑO \\
\hline Psicología del pueblo español & Revista Nuestro Tiempo & Manuel Sales y Ferré & 1902 \\
\hline $\begin{array}{l}\text { Constitución y vida del pueblo español: estudio sobre } \\
\text { la etnografía y la psicología de las razas de la España } \\
\text { contemporánea }\end{array}$ & Editorial Internacional & Vicente Gay y Forner & 1905 \\
\hline $\begin{array}{l}\text { Nuestro carácter. Reflexiones acerca del estado psíquico- } \\
\text { orgánico de nuestra raza y manera de robustecerla }\end{array}$ & Editorial Bailly-Baillere & Enrique Mateo Barcones & 1905 \\
\hline El histrionismo español. Ensayo de psicología política & Imprenta de Henrich & Eloy Luis André & 1906 \\
\hline El alma española & F. Sempere y Compañía & Ricardo Rojas & 1907 \\
\hline El alma española. Ensayo de una psicología nacional & $\begin{array}{l}\text { Centro Editorial de } \\
\text { Góngora }\end{array}$ & Gustavo La Iglesia García & s.f. \\
\hline El alma nacional, sus vicios y sus causas & Imprenta Cervantina & Marqués de Dosfuentes & 1915 \\
\hline Psicología del pueblo español & F. Peña Cruz & Diego Abad de Santillán & 1917 \\
\hline La nación sin alma: ensayos políticos sobre la crisis española & El liberal & Juan Guixé & 1918 \\
\hline El temperamento español. La democracia y la libertad & Minerva & Álvaro de Albornoz & 1920 \\
\hline Tierra y alma española & $\begin{array}{l}\text { Sucesores de } \\
\text { Rivadeneyra }\end{array}$ & Julio Cejador y Frauca & 1923 \\
\hline Sensibilidad española & Imprenta de Juan Pérez & Juan Guixé & 1927 \\
\hline $\begin{array}{l}\text { Ingleses, franceses y españoles. Un ensayo de psicología } \\
\text { comparada }\end{array}$ & M. Aguilar & Salvador de Madariaga & 1928 \\
\hline Españolismo. Pueblo y conciencia nacional & $\begin{array}{l}\text { Sucesores de } \\
\text { Rivadeneyra }\end{array}$ & Eloy Luis André & 1931 \\
\hline Reflexiones sobre el alma y el cuerpo de la España actual & Editorial Plutarco & Romero Flores & 1933 \\
\hline $\begin{array}{l}\text { La psicología del pueblo español: ensayo de un análisis } \\
\text { biológico del alma nacional }\end{array}$ & Librería Bergua & José Bergua & 1934 \\
\hline
\end{tabular}

Fuente: elaboración propia

fundamentos de la manera de ser y actuar del español, lo que más nos interesa estudiar aquí es cómo, a través de tal óptica, sopesaron concretamente las posibilidades de alcanzar un "ciudadano español" autogobernado. Presentamos un análisis de esta cuestión en las obras publicadas en la primera mitad del período ocupado por el género, concretamente hasta el año 1918. Estudiamos así de qué manera se recogió inmediatamente la herencia psicológica y política del regeneracionismo español y cómo esta se rearticuló en torno a la figura del autogobierno, en tanto que propia de la modernidad occidental.

\section{La herencia regeneracionista: auge y caída del genio español}

En continuidad con el regeneracionismo, las obras que seleccionamos construyen, a grandes rasgos, las peculiaridades de caso español a partir de dos fundamentos: por un lado, la nómina explícita de atributos caracteriológicos positivos y negativos singulares del español; por otro lado, alguno de los tres grandes marcos psicogenéticos implícitos de los que, en mayor o menor interacción, derivar la emergencia de tales atributos. El primero de esos marcos se basa en aspectos geoclimáticos de carácter predarwinista, planteando un isomorfismo entre las cualidades del clima y el territorio y carácter de los habitantes. Detrás de los otros dos, late la influencia del darwinismo spenceriano, derivando hacia una etnopsicología determinista de doble filiación. La primera de ellas trasluce un marco de carácter más racial, según el cual las características psicológicas peculiares de una comunidad nacional de deben a la herencia de las características propias de una supuesta raza originaria y su ulterior mezcla con las cualidades aportadas por otras razas en el devenir histórico. La segunda filiación tiene un 
carácter más ambientalista, planteando que las características psicológicas actuales son resultado de una selección ambiental, bien relativamente reciente -en línea con la perspectiva del determinismo positivista- bien resultado de un amplio proceso sociohistórico -en coherencia con una perspectiva más psicohistórica-.

Estas grandes directrices, concretamente las perspectiva geoclimática y racial, convergen para establecer la definición de unas cualidades caracteriológicas en el español. asociadas habitualmente al individualismo, la energía y el idealismo de una supuesta raza ibérica originaria. Así, para el Marques de Dosfuentes:

El gusto ibero, recio, desordenado, salvajemente viril, altivo, adusto, aunque aristócrata por abolengo de estirpe, es a despecho de su distinción racial, rebelde, indómito levantisco, descompuesto, enemigo por instinto de todo aquello que lo sistematice centralizándolo con oficinas del alma. Bravío, brutal si se quiere, no se acomoda con la uniformidad sin que ello implique la idea de desorden. (Dosfuentes, 1915, p. 43)

Como trasluce la última parte de la cita, las cualidades originarias son ya de por sí ambivalentes, porque al tiempo que impulsan los más altos logros históricos de la raza -básicamente la Reconquista frente al "invasor" musulmán y la Conquista de América- también arraiga en ellas el germen de lo que causará su decadencia. Para la explicación de este último proceso, sin embargo, es necesaria la intervención puntual de otras variables que nuestros autores conjugan a partir de la combinación de aspectos de la perspectiva ambientalista y racial. Estas variables fortuitas (históricas, ambientales o raciales) se consideran extrañas o ajenas a las condiciones naturales originarias, y su efecto es capaz de desviar al pueblo español de un devenir histórico exitoso. Así, autores como Abad de Santillán (1897-1983) ${ }^{10}$

10 Diego Abad de Santillán es, en realidad, el seudónimo de Sinesio Baudillo García Fernández, conocido militante anarquista que desarrolló su lucha política tanto en España como Argentina. Sorprendentemente, a pesar de su temprano compromiso anarquista, su Psicología del Pueblo español comparte rasgos evidentes con el conjunto del género. En la línea de éste, identifica los supuestos desplazan esa responsabilidad hacia el gobierno de las masas nacionales, una estrategia de salvaguarda identitaria habitualmente utilizada desde el primer regeneracionismo:

De nuestra historia se deduce que es la raza española un tesoro de energías y que sabe gastarlas totalmente y caer rendida, postrada, en actitud de muerte; pero también sabe por su dureza reponerse con extraordinaria prontitud; se deduce también que es sumamente maleable y leal a su Rey; así, siendo éste inteligente, la nación es con facilidad conducida a contribuir con las más adelantadas en la obra del progreso; si el Soberano es idiota, lo más entusiastas españoles pierden toda la esperanza en la virtualidad étnica. (Abad, 1917, pp. 81-82)

Este tipo de procesos externos y alterizantes producen, para nuestros autores, la perversión de los caracteres originarios transformando, básicamente, el individualismo en egoísmo, la energía en apatía y el idealismo en fantasía; todo lo cual conduciría al pueblo español a la degeneración. Todos nuestros autores, sin excepción, advierten explícitamente que esas alteraciones caracterológicas se detectan, en diferentes grados y modos, en todas las clases sociales españoles de su época. Su horizonte de contraste tiene, además, un carácter marcadamente sociodarwinista: implica sopesar las oportunidades identitarias en la lucha por la vida y la selección natural dentro de una lógica "ambiental" definido por la lógica internacional del progreso, el mercado, el desarrollo industrial y el bienestar social.

\section{El pueblo español: la materia prima psicológica del autogobierno}

El contexto comentado sirve de justificación para que nuestros autores aboguen por una inaplazable

vicios y virtudes del alma española y las claves de su regeneración, incluyendo la reivindicación de la autonomía autogobernada para el ciudadano. Este estudio casi puede considerarse una excepción dentro de una obra dedicada exclusivamente al pensamiento anarquista con títulos como el Anarquismo en el movimiento obrero (1925), El movimiento anarquista en Argentina (1930) y La revolución y la guerra en España (1938). 
reconstrucción de la subjetividad nacional; un proceso que, en todo caso, exige preservar la auténtica esencia caracteriológica de lo español. En el discurso de nuestros autores, renunciar a esta última condición implicaría un desnaturalización del principio identitario que garantiza la singularidad genuina de la nación española en el concierto internacional. Por ello, la operación refiguradora consiste más bien en retornar a la esencia auténtica, incorrupta y conservada, a la manera romántica, en el pueblo llano. Tal interpretación estaba completamente fraguada desde el regeneracionismo de finales del siglo XIX, pero nuestros autores, sobre todo Vicente Gay ${ }^{11}$, Eloy Luis André, el Marqués de Dosfuentes y Abad de Santillán, volverán con especial entusiasmo a ella. En todos esos casos, resulta fundamental sondear las simas recónditas de la subjetividad colectiva, si el objetivo es "regenerarla" y devolverla a un cauce histórico aceptable. En palabras de Vicente Gay (1876-1949):

Nuestra constitución natural, verdadera, está oculta (...). Volver los ojos a nosotros mismos es buscarnos para tener conciencia de nuestra personalidad y de la manera de ser de nuestra vida, que difícilmente podrá encauzarse si nuestra guía no arranca del conocimiento de la realidad y no de las inspiraciones de la fantasía. (Gay, 1905, pp. 13-15)

Leído en términos más técnicos que idealistas, este tipo de inquietudes reflejan una diatriba mucho más terrenal y urgente: la pregunta suscitada es hasta qué punto es posible la transformación de la subjetividad agotada y propia del viejo régimen imperial español periclitado -esto es, la de un súbdito configurado sobre la creencia religiosa y la tradición-, en otra que se adecúe bien a la construcción de un Estado nación moderno y liberal a la manera de las potencias anglosajonas -esto es,

11 Vicente Gay y Forner fue catedrático de Economía y Hacienda durante la etapa liberal española (1874-1931) y terminó evolucionando hacia posiciones políticas abiertamente fascistas y racistas. Ya antes de la Guerra Civil, reclamaba el resurgir del imperialismo español a través de una nueva cruzada colonialista. Entre sus títulos cabe mencionar Impresiones en la América española (1915), Las constituciones politicas: el verdadero gobierno de los pueblos (1930) o La revolución nacional-socialista (1934). la propia del ciudadano liberal que habita la ciudad industrial-. El contraste nacional planteado por Luis André, su descripción de los engranajes psicológicos y, al tiempo, morales de dos versiones contrapuestas de la subjetividad, es muy perspicaz a ese respecto:

Un norteamericano, un neoyorkino, tienen ante sus ojos un mundo real y moral distinto del nuestro: la ciudad es inmensa, su vivir intensísimo, un vivir hijo del esfuerzo personal exclusivo, que supone un avistamiento en la mente y tenacidad en la acción, un vivir para almas libres, para personalidades poderosas. El hijo de los campos castellanos tiene una acción soñolienta y perezosa, monótona y rutinaria, y piensa pobremente, sin poseer jamás iniciativas, porque no se le presentan casos nuevos; su pensar es hijo de la experiencia pero no padre de ella; no puede tener la misma concepción de la vida, ni fijarle la misma trayectoria, que el anterior. (Luis André, 1906, pp. 193-194)

En último término, el problema fundamental que se deriva de reflexiones como la de Luis André es cómo salvar la distancia entre la autenticidad y singularidad de lo español y el modelo anglosajón de subjetividad que se encarna en el ciudadano reflexivo y autogobernado.

Este último se intuye como el resultado de un proceso psicohistórico y etnopsicológico que, a diferencia del estancamiento o desvío atávico español, sí ha permitido un desarrollo óptimo de la conciencia intencional. El camino psicogenético anglosajón permite una interiorización racional normas y reglas colectivas, dando lugar también a la conciencia moral. Gracias a ella, el individuo puede actuar de forma libre, autónoma y relativamente igualitaria, sin que esto sea en ningún caso incompatible con el comunitarismo o la sociabilidad. En palabras de Sales y Ferré:

A medida que el vínculo social arraiga y se fortifica en la conciencia de cada individuo, éste se forma, se emancipa, se constituye, adquiere más libertad y más derechos, de los que, penetrada su conciencia de la conciencia colectiva, no ha de usar sino para 
Claves psicológicas fundacionales del aUtogobierno CiUdadano: la

"PSicología del PUEblO ESPAÑOl” COMO ESTUdiO DE CASO (1902-1918)

el bien de la sociedad, al tiempo que para el suyo propio. En este grado de desarrollo, el bien social y el bien individual son uno y el mismo. Por esto, en las sociedades civilizadas, los individuos son más libres y juntamente más disciplinados. Libre y modelo de disciplina social es el pueblo inglés. (Sales, 1902, p. 11).

Garantizar esta sociabilidad de base es lo que permite al anglosajón despreciar las coerciones externas del intervencionismo estatal y tildarlas de contrarias a la libertad. La afinidad de nuestros autores por esta perspectiva es completa, idealizando al ciudadano libre capaz de tomar conciencia de su propia conducta y guiarla responsable y activamente en beneficio y progreso de todo el colectivo; esto es, de la convivencia, el progreso y el orden público. Pero la sociabilidad de base no es solo el contrapunto del estatalismo, sino también de los excesos del individualismo que, en contraste con el español, tan bien temperado aparece en el espíritu anglosajón. A ese respecto, Abad de Santillán plantea como:

El individualismo español es un individualismo que tiene principalmente su base originaria en la falta de conciencia social: individualista es el que estando en plena conciencia social, se resta de ella y se reconcentra en sí; nosotros no somos colectivistas porque en nuestra mente no entró el perfecto concepto de sociedad. Nuestra patria es nuestro pueblo; sólo el pueblo conocemos (...) en general, las personas que no son del círculo de nuestra propia vida nos son indiferentes. (Abad, 1917, p. 257)

En último término, la gran mayoría de los problemas sociopolíticos españoles será tratada como síntomas mórbidos de esta suerte de alteración individualista de la personalidad nacional. A partir de ella, se definirán modelos de ciudadanía opuestos punto por punto a los asociados al ideal anglosajón. Así, es habitual que nuestros autores localicen síntomas de egoísmo, corrupción y miedo al progreso en los poderes públicos; de picardía, vagancia y conflictividad social en las clases trabajadoras y de impotencia, desamparo y escepticismo en las clases medias. En todo caso, las posibilidades de sanar el maltrecho espíritu nacional y, por ende, de una recuperación socioeconómica no podían ser descartadas.

\section{Teorías y tecnologías del yo ciudadano: individualismo y reeducación}

Teniendo en cuenta este panorama de contrastes y la necesidad urgente de rediseñar la subjetividad nacional sin abandonar sus supuestas esencias, en los textos de nuestros autores pueden destacarse dos estrategias resolutivas. Ambas pueden aparecer, por supuesto, de forma de complementaria.

La primera de ellas tiene un carácter más teórico y se sitúa tácitamente en el marco etnopsicológico racial. A partir de él, todos nuestros autores tratan de revalorizar y actualizar el carácter individualista del español en tanto que fundamento de autonomía y libertad personal. Para cimentar y enaltecer tal equivalencia etnopolítica, algunos autores como Luis André o el Marqués de Dosfuentes llegarán incluso a establecer un cerrado paralelismo identitario entre el supuesto individualismo del pueblo español y el inherente al pueblo británico. Así, el Marqués de Dosfuentes planteará cómo:

(...) la analogía entre iberos y británicos tomó su origen en las capas más hondas donde se nutren las raíces de ambos pueblos. En ambas islas, por razón de ser tales, se ha conservado un profundo sedimento de aquella raza que un día dominó a Europa, cuando las tribus pregermanas no existían (...) en ambas islas supervivencias atávicas han podido subsistir con mayor fuerza que en otros pueblos de condiciones análogas, sobreponiéndose a los influjos extranjeros. (Dosfuentes, 1915, p. 37)

Evidentemente, la analogía caracteriológica está orientada a garantizar la existencia, aún hoy, de excelentes actitudes naturales en el pueblo español; particular y felizmente, de aquellas necesarias para desarrollar la misma iniciativa personal y capacidad productiva que caracteriza a los ingleses o a cualquier otro pueblo desarrollado y civilizado.

Salvaguardada por tanto la bondad y autenticidad de la materia prima caracteriológica, la segunda estrategia de este proceso civilizatorio tiene un 
carácter más técnico y orientado a la intervención. Se desplegará desde el marco ambientalista, bien desde su versión genuinamente romántica -como manera de recuperar el verdadero ser español, caso ejemplar de el Marqués de Dosfuentes o Abad de Santillán-, bien desde su perfil más degenerado y determinista, como manera de paliar las distorsiones infringidas en el ser nacional, caso ejemplar de Sales y Ferré o Mateo Barcones ${ }^{12}$ o bien desde una hibridación difusa entre ambas alternativas argumentativas -como ocurre en la obra de Vicente Gay-. Sea como fuera, lo que también es evidente es que la mayoría de esos medios técnicos operan ya dentro de la ingeniería social propia de modernidad, tal y como se desprende de conclusiones como la de Mateo Barcones:

(...) expuestas las causas generales del decaimiento de nuestra raza, de las que debemos eludirnos, robusteciendo nuestra memoria por el adiestramiento, rehabilitando la fuerza de nuestra voluntad por la educación, y normalizada la inteligencia por los preceptos o cánones de una buena y sabia higienización, habremos conseguido enmendar nuestros arraigados y perjudiciales defectos psiquico-orgánicos, adquiriendo un crédito de seria respetabilidad del que hoy carece nuestro carácter nacional y de raza. (Mateo, 1905, pp. 150-151)

En el resto de las obras, higiene y educación pueden aparecer junto a otro tipo de tecnologías sociales -como la criminología, la eugenesia o el periodismo como generador de opinión pública-, pero siempre asociadas al impulso de la reeducación, la productividad y el control de las masas poblacionales, respecto del contexto de la modernidad industrial. Con todo, en algunos casos también se cuenta con aprovechar los principios de regulación

12 Enrique Mateo Barcones era médico militar del ejército español y, quizá por ello, en su obra despliega una profusa retórica médica y quirúrgica, para explicar las causas del deterioro caracterológico español y proponer medidas terapéuticas. En todo caso, esto converge con claves ya propuestas en el discurso regeneracionista original, donde la mirada psicofisiológica oscila continuamente entre la literalidad y la alegoría. Otra obra suya fue Estudios para una nosología filipina (1895), editada pocos años antes de que España perdiera definitivamente la colonia asiática ante Estados Unidos. comportamental tradicionalmente arraigados en las costumbres religiosas españolas.

Considerando el horizonte autogubernativo, aquí vamos a comentar con un poco más de detenimiento la cuestión pedagógica, por su evidente importancia en todas las obras estudiadas, y la religión, por su relevancia en lo que tiene que ver con las continuidades culturales respecto de prácticas de subjetivación previas existentes en España.

\section{Pedagogía ciudadana: la iniciativa del yo nacional}

Sobre todo en las obras de Mateo Barcones, Eloy Luís André, Gustavo La Iglesia y García y Juan Guixé, las funciones de la pedagogía se asocian a la imagen infantilizada del pueblo español. Gustavo La Iglesia y García, por ejemplo, lo presenta como la tragedia de muchos españoles que:

(...) llegan a la plenitud de la vida con tan escasas energías, con tanta timidez, con tanta irresolución, que aparecen cual si fueran medrosos niños, o bien versátiles, inconscientes y tornadizos adolescentes. (...) aceptan con docilidad extremada las opiniones hechas, por disparatadas y absurdas que estas sean, rechazando en ocasiones los juicios más sanos, por no haber cultivado bien su inteligencia para poder comprenderlos y apreciarlos. De este modo resultan incapacitados para librarse de la vergonzosa tutela a que están sujetos. (La Iglesia y García, s. f., p. 84)

En línea con las reflexiones a propósito del autogobierno, el español aparece aquí como un sujeto incapaz de hacerse cargo de su propia conducta y, por tanto, condenado a sufrir las arbitrariedades de una tutorización externa, bien de carácter nacional o bien, incluso, internacional. Frente a ello, la pedagogía moderna se convierte en la vía más adecuada para desarrollar la conciencia y voluntad desde la infancia. El proceso, en todo caso, debe ser tremendamente cuidadoso, para no incurrir en los mismos errores que supuestamente viene a combatir, pero sobre todo por el alcance de los objetivos que supone un manejo adecuado de la herramienta pedagógica. En palabras de Mateo Barcones: 
El procedimiento educativo debe ser siempre, (...), metodizado, y, en particular, cuando se aplica para conseguir el perfeccionamiento de la voluntad, pues si no preside la educación de ésta un plan sancionado por la experiencia, y confirmado por la práctica, se entrega al educando en brazos de la fatiga, tanto psíquica como muscular y orgánica. (...) la educación es un factor de importancia suma en el estado sociológico de los pueblos, de las modernas y aun de las futuras democracias, que son las que están llamadas a gobernar el mundo actual y venidero. (Mateo, 1905, p. 118)

Como en el caso de Mateo Barcones, resulta evidente que el tipo de pedagogía que persiguen nuestros autores no toma al niño como fin en sí mismo. No están ausentes cuestiones como la promoción de la creatividad, la imaginación e iniciativa personal, en línea con el ideal individualista anglosajón. Pero el objetivo es, ante todo, optimizar los recursos personales infantiles pensando en que el sujeto tiene que alcanzar la madurez y colaborar activamente en el proyecto social. Teniendo esto en cuenta, no es de extrañar que las reflexiones pedagógicas de autores como Mateo Barcones o Gustavo La Iglesia y García conecten directa y genéricamente con descripciones muy detalladas de las disfunciones de la mente española; aspecto, este último, que, en todo caso, está presente en prácticamente la totalidad de las obras estudiadas.

A ese respecto, y como muestra ejemplarmente el argumento de Mateo Barcones que venimos siguiendo, la mayoría de las descripciones mórbidas de la mente española están claramente asociadas a la fatiga y el inmovilismo personal y, por ende, social:

(...) la fatiga que domina a nuestra raza, a causa, en unos (clase media de nuestra sociedad), de un adiestramiento a destiempo, e intensivo y mal dirigido cuando la edad no es la indicada, ha exaltado nuestra memoria, nuestra imaginación y asociación feliz de ideas, disminuyendo de una manera palmaria el poder de atención; y en otros (clases aristocráticas y proletarias de las mismas), la falta completa, en la inmensa mayoría, del asiestamiento físico en los pri- meros, e intelectual en los segundos, ha hecho, por falta del ejercicio funcional del sistema muscular y psíquico, que nos encontramos igualmente fatigados, amnésicos, neurasténicos, y, en su consecuencia, enflaquecida la memoria de la inmensa mayoría de los individuos de nuestra raza. (Mateo, 1905, pp. 96-97)

En la línea de la cita, el argumento prototípico de nuestros autores supondrá que la fuerza rutinaria de los hábitos -encarnadas en el peso reproductivo de la tradición-, los excesos memorísticos -obstaculizadores del descubrimiento y la novedad- o la arbitrariedad y debilidad en la asociación de ideas -desencadenadora de una fantasía hipertrofiadacercenaba las condiciones de realismo y progreso exigidos por los retos de la modernidad, la civilización y el progreso. Desde la perspectiva liberal, la pedagogía era, casi arquetípicamente, la herramienta más adecuada para combatir en todos esos frentes psicológicos, pero no la única.

\section{Religiosidad ciudadana: el autocontrol del yo nacional}

Exceptuando quizás las de Sales y Ferré y Vicente Gay, la religiosidad aparece en todas las obras estudiadas, guardando una clara relación de continuidad histórica y cultural con las nuevas prácticas modernas de subjetivación y autorregulación del comportamiento. En cierto sentido, estas prácticas hibridarán tradición y modernidad para preservar o rearticular formas de convivencias propias de viejo régimen, sobre todo a la hora de poner límites a las versiones más radícales del individualismo, el colectivismo y el materialismo, derivadas de la apertura liberal y democrática.

Así, en el caso español, la tecnología religiosa permite articular un diseño de la subjetividad equilibrado entre la demanda de felicidad -propia de la vida "para este mundo" y asociada al modelo de progreso material e industrial de la modernidad $-\mathrm{y}$ la necesidad del sacrificio personal. El primer término de la ecuación invoca la pertinencia de los valores morales como fines humanos necesarios: una advertencia o precaución ante los excesos del puro materialismo. El segundo término, por su parte, 
establece la prioridad de la solidaridad comunitaria frente al egoísmo individual.

En ambos frentes jugarán un importante papel tanto las tecnologías propiamente católicas como un eco de las protestantes en su versión más calvinista. Las primeras estaban ligadas al ejercicio individual de la responsabilidad culposa y controladora del libre albedrío y las pasiones, mientras que las segundas inspiraban la pertinencia de una vida sencilla y equilibrada, basada en la austeridad y la moderación individual. En palabras de Gustavo La Iglesia y García:

(...) la única felicidad posible, el mayor número de verdades satisfactorias, la tranquilidad de las conciencias y los más puros goces del espíritu están en la vida sencilla, conseguida fácilmente cuando la sencillez de las costumbres influye en nuestras acciones. Es ésta la mejor orientación de la existencia, la línea de conducta que ahorra más sinsabores, aleja más peligros, evita más disgustos y hace que no aumenten los torcedores de la conciencia, ofreciendo además la ventaja de que limita mucho las necesidades. (s. f., p. 94)

Con este austero control religioso de la vida interior y el comportamiento exterior, autores como La Iglesia y García trazan una vía de contacto inusitado con las fuentes del autogobierno racionalizado y bien temperado, propio de la subjetividad anglosajona.

En todo caso, conviene recordar que, frente las urgencias españolas, la tesis etnopsicológica suponía que el pueblo anglosajón había alcanzado el ideal autogobiernativo, gracias a un desarrollo progresivo y constante de la conciencia reflexiva. Esta cuestión es importante porque, junto a la pedagogía, la religión parece ofrecer una vía real por la que avanzar más rápidamente hacia la regeneración reflexiva y activa. Más aún, permitía esquivar las versiones más radicales del fatalismo positivista que, en la época de nuestros autores, supeditaba totalmente la actividad humana a determinismos vestigiales raciales y ambientales-. Las suspicacias ante estos planteamientos están muy presentes cuando autores como Abad de Santillán plantean que:
(...) hemos considerado al individuo y a la sociedad como seres pasivos frente a la influencia del medio; las concepciones darwinistas dominan el mundo de las ciencias naturales y sociales quizá excesivamente. (...) Cierto es que [sociedad e individuo] se adaptan al medio, pero también adaptan el medio a sus necesidades, y esta segunda operación es más propia, porque la vida es algo activo, la pasividad se traduce por la muerte. No se duda de la influencia de la naturaleza ambiente sobre los pueblos, ni de la influencia de los pueblos sobre la naturaleza ambiente. (Abad, 1917, p. 20)

Efectivamente, el determinismo meramente responsivo suponía un principio de irresponsabilidad antropológica que, a todas luces, resultaba incompatible con el autogobierno y la iniciativa individual que fundamentaba la agenda reformista del liberalismo español, en general, y de nuestros autores, en particular. Conviene precisar, en todo caso, que tal agenda tiene sus propias formas de interpretar los fines políticosociales, ideales de una subjetividad autogobernada o autorregulada.

\section{Los límites políticos del autogobierno psicológico}

Como planteábamos al principio de este trabajo, difícilmente se puede presuponer un proyecto de autogobierno psicológico ideal y homogéneo para todo el mundo occidental. En el caso de nuestros autores, el hecho de promover técnicamente la iniciativa y responsabilidad del ciudadano español-vía pedagogía, religiosidad o cualquier otra-, no implica un interés orientado a optimizar sus posibilidades de protagonizar y participar en la construcción del modelo de convivencia y gobierno. Como ya detectábamos cuando hablábamos de pedagogía, la intención es instituir un mecanismo de interiorización psicológica que rebase los deseos o esperanzas individuales. Esta teoría de la actividad está muy clara en diversos planteamientos salvíficos que, de hecho, convergen a la perfección con la retórica religiosa ya comentada. Es el caso del argumento desplegado, por ejemplo, en la obra de La Iglesia y García: 
Hay que convertir la actividad en una virtud: por ella lograremos salvarnos; hay que emplear contra la indolencia nacional los bienhechores estímulos del trabajo. Este es un remedio eficaz y poderoso que, aplicado a la masa indiferente del país, logrará conducirla por los mejores y más rectos caminos, y con respecto a muchos individuos representará una verdadera regeneración. Siendo, como es, la pereza una de las peores y más perniciosas dolencias, combatirla por los todos los medios posibles y adecuados es velar por la salud colectiva y por la salud individual. (s. f., p. 122)

Frases como esta exponen bien a las claras los dos objetivos básicos del plan autogubernativo de nuestros autores: maximizar la capacidad y flexibilidad productiva, base del progreso propio de la modernidad -frente al inmovilismo cíclico del viejo régimen- y lograr la supeditación de todo individuo al proyecto colectivo, fundamento de un orden armónico y, al tiempo, permeable de clases -frente a la rígida estamentalización del viejo régimen-.

Así las cosas, no es de extrañar que todos nuestros personajes, siendo promotores del autogobierno, también se muestran suspicaces con la democracia. Tal es el caso que hasta liberales reconocidos como Luis André llegan a objetar cuestiones como que:

El nuevo liberalismo, que debe consistir en el making del selfman, no puede acabar con la superioridad íntima del alma, no puede consolidar igualitarismos estúpidos (...). El nuevo liberalismo, al proclamar la democracia como fruto de nuestra autonomía personal y de nuestra capacidad social para organizar el Estado y determinar sus funciones, no puede cortar de raíz la aristocracia de las almas, su riqueza nativa, su fuerza, su potencia natural, que en el mundo íntimo se manifiesta y obra (Luis André, 1906, pp. 217-218).

Y de la misma manera que Luis André retorna al argumento intrapsíquico para defender la imposibilidad de que todos los sujetos sean iguales por naturaleza, otros como Gustavo La Iglesia y García no dudarán en psicopatologizar y criminalizar las reivindicaciones anarquistas que abogaban por la igualdad y la desaparición de las clases sociales. En definitiva, la psicologización de la subjetividad autogobernada, propia del espectro liberal, se juega en muchos frentes políticosociales; al menos en el caso español, todos los necesarios para resolver la difícil ecuación de un ciudadano medio a caballo entre los atavismos y rutinas subjetivas del viejos régimen y la aceleraciones y fracturas identitarias de la modernidad. En previsión de desajustes, el sujeto provisional ideado por nuestros autores tiene que ser consciente de su vida para cumplir con dos objetivos básicos: su autorregulación, aceptando el lugar que le corresponde en el orden social -por méritos y capacidad-, y su propio desarrollo activo, a partir de las tareas específicas que tal lugar supone.

Siendo así, y yendo más allá del sujeto individual, iquién se encarga entonces de gestionar el autogobierno colectivo si el ciudadano ya no tiene nada que ver en ello? Los textos de nuestros autores nunca terminan de ser completamente explícitos a este respecto. Pero, habida cuenta de la corrupción incívica atribuida a las clases directoras tradicionales y las quejas por el protagonismo políticosocial supuestamente sustraído o usurpado a las clases medias, resulta evidente que estas últimas se erigen como la verdadera autoconciencia para el gobierno de lo público. En ello hay, seguramente, síntomas todavía muy imprecisos de un proyecto históricosocial ampliamente tecnocrático e ingenieril, fiado y protagonizado por los representantes por excelencia de las clases medias de la modernidad. En ellas se fraguarán, desde luego, los intelectuales y científicos artífices del diseño social, aunque también, en buena medida, los empresarios empeñados en impulsar, a veces a cualquier precio, su desarrollo material y económico (véanse Rosa, Castro, \& Blanco, 2007).

\section{Psiudadanos: a modo de conclusión}

Este trabajo toma como objeto de estudio varias obras fundacionales del género de la Psicología del Pueblo Español sobre un supuesto fundamental: estas reflejan el discurso a través del cual se psicologiza el sujeto político español, respecto de un proyecto sociohistórico más amplio y propio de la 
modernidad liberal de principios del siglo XX. Un dominio de construcción de la subjetividad crucial para esa agenda fue el de una ciudadanía autogobernada, figura global que adquirirá contornos políticos específicos, en función de las diferentes condiciones socioculturales de posibilidad, bajo las que se implementará.

Nuestro estudio del caso español revela que la reivindicación entusiasta de este autogobierno no estaba necesariamente acompañada de una amplia participación en las decisiones políticas y la construcción democrática del Estado nación. La opinión reflejada en las obras que hemos analizado está muy lejos, por tanto, de las versiones más progresistas del liberalismo, caso de, por ejemplo, las de pragmatistas estadounidenses como John Dewey, James Baldwin, Jane Addams o Arland Weeks. Aún en su convicción afín al liberalismo, los autores que hemos estudiado se mostraban más bien escépticos ante la posibilidad inminente de una construcción ciudadana basada en la psicogénesis intersubjetiva o dialógica de la conciencia solidaria, autorreguladora y emprendedora; la misma que supuestamente caracterizaba la subjetividad anglosajona. Tal posibilidad aparecía supuestamente lastrada por otros condicionantes psicológicos de más envergadura, rasgos caracteriológicos de insolidaridad y apatía definidos desde marcos de interpretación deterministas, de carácter etnopsicológico y psicohistórico.

Para rebasar estos condicionantes psicológicos nuestros autores confiarán en la moderna ingeniería social-sobre todo pedagógica-, pero sin renunciar al remozo de las tradicionales prácticas religiosas de subjetivización. Con todo, se trataba de una apuesta interventiva de lenta y trabajosa resolución. En el fondo, nuestros autores la observaban como una ortopedia o sucedáneo de la elaborada psicogénesis la subjetividad anglosajona. Quizá por ello, el proyecto de autogobierno individual de nuestros personajes se limitaba a optimizar las posibilidades de una condición sacrificada y productiva en la masa poblacional. Al menos esta opción parecía evitar, por la vía rápida, la exclusión de España del proyecto moderno. Por supuesto, complementariamente, esto también privilegiaba el propio rol de la clase intelectual como diseñadora y administradora de la actividad política y económica colectiva.

Sea como fuere, desde el punto de vista genealógico, el discurso de las obras que componen el género de la psicología del pueblo español refleja al tiempo que inspira las posibilidades remotas de un modelo de ciudadano participativo en el origen de España como Estado nación moderno. De paso, también permite certificar el gran peso que la psicología tuvo como argumento legitimador de las diversas utopías sociales de la modernidad, las mismas que el transcurrir del siglo se encargó de sancionar como realizables o improbables.

\section{Referencias}

Abad, D. (1917). Psicología del pueblo español. Madrid: Imprenta de Felipe Peña Cruz.

Alberola, A. (1987). Estudios sobre Rafael Altamira. Alicante: Instituto de Estudios Juan Gil-Albert.

Altamira, R. (1997). Psicología del pueblo español. Madrid: Biblioteca Nueva. (Original publicado en 1902)

Blanco, F. (2002). El cultivo de la mente: un ensayo teóricocrítico sobre la cultura psicológica. Madrid: Antonio Machado.

Carpintero, H. (1998). La psicología en la España de 1898. Revista de Historia de la Psicología, 19(1), 5-42.

Casas, A. M. (2009). Salvador de Madariaga. Madrid: AECI.

Castro, J. (2004). La psicología del pueblo español: el papel del discurso psico-sociológico en la construcción de la identidad española en torno a la Crisis del 98 (Tesis doctoral inédita). Universidad Autónoma de Madrid, España.

Castro, J. (2008). Eloy Luis André (1876-1935) e as identidades histórico-culturales da psicoloxía. Cadernos de Psicoloxia, 32, 103-134.

Castro, J., \& Lafuente, E. (2007). Westernalization in the mirror: On the cultural reception of Western psychology. Integrative Psychological and Behavioral Science, 41(1), 106-113.

Castro, J., Lafuente, E., \& Jiménez, B. (2009). The soul of Spain: Spanish scholastic psychology and the making of modern subjectivity (1875-1931). History of Psychology, 12(3), 132-156. 
Dosfuentes, M. (1915). El alma nacional, sus vicios y sus causas. Madrid: Imprenta Cervantina.

Foucault, M. (2000). Vigilar y castigar. Madrid: Siglo XXI.

Foucault, M. (2007). Security, territory, population. London: Palgrave Macmillan.

Gay, V. (1905). Constitución y vida del pueblo español. Madrid: Administración San Roque.

Heater, D. (2004). A brief history of citizenship. New York: New York University Press.

Kymlicka, W. (1995). Multicultural citizenship: A liberal theory of minority rights. Oxford: Oxford University Press.

La Iglesia y García, G. (s. f.). El alma española. Ensayo de una psicología nacional. Madrid: Centro Editorial de Góngora.

Llavona, R., \& Bandrés, J. (1999). Aportación de Rafael Altamira (1866-1951) a la psicología. En A. Romero, J. Casco, F. Fuentenebro \& R. Huertas (Eds.), Cultura y psiquiatría del 98 en España. Madrid: Neocisne Ediciones.

Luis André, E. (1906). El histrionismo español. Barcelona: Imprenta Henrich.

Mateo, E. (1905). Nuestro carácter. Madrid: Librería Editorial de Bailly-Bailliere e Hijos.

Miller, P., \& Rose, N. (2008). Governing the present. Cambridge, UK: Polity Press.

Morón, C. (1998). El "Alma de España". Cien años de inseguridad. Madrid: Ediciones Nobel.

Núñez Encabo, M. (1976). Manuel Sales y Ferré. Los orígenes de la sociología en España. Madrid: Cuadernos para el Diálogo.

Purvis, T., \& Hunt, A. (1999). Identity versus citizenship: Transformations in the discourses and practices of citizenship. Social Legal Studies, 8(4), 457-482.
Quintana, J. (1998). Fundamentos teóricos de la "psicología del carácter español" de D. M. de Unamuno. Esbozo de una "Psicología de los pueblos". Revista de Historia de la Psicología, 19(1), 43-79.

Quintana, J., Rosa, A., Huertas, J. A., \& Blanco, F. (Eds.). (1998). La incorporación de la psicología científica a la cultura española. Siete décadas de traducciones (1868-1936). Madrid: UAM Ediciones.

Rodríguez, J., Sitges, E., Jarabo, C., Estévez, C., \& Brisoire, A. (2002). Análisis de contenido de la obra "Psicología del Pueblo Español" de Rafael Altamira. Revista de Historia de la Psicología, 23(34), 293-305.

Rosa, A., Castro, J., \& Blanco, F. (2007). Otherness in historically situated self-experiences. A case-study on how historical events affect the architecture of the self. En L. M. Simão \& J. Valsiner (Comps.), Otherness in question: Labyrinths of the self (pp. 229-256). Charlotte, North Carolina: Advances in Cultural Psychology.

Rose, N. (1989). Governing the soul. London: Free Association Books.

Rose, N. (1996). Inventing ourselves: Psychology, power and personhood. Cambridge: Cambridge University Press.

Sales, M. (1902). Psicología del pueblo español. Nuestro Tiempo, 2(13), 9-20.

Sluga, G. (2006). The nation, psychology, and international politics, 1870-1919. New York: Palgrave Macmillan.

Varela, J. (1999). La novela de España. Los intelectuales y el problema español. Madrid. Taurus.

Yebes, J. A. (2002). La España moderna. Catálogo de la editorial e indice de las revistas. Madrid: Libris. 
